\title{
THE BENEFIT PROVISIONS OF STATE UNEMPLOYMENT INSURANCE LAWS
}

\author{
EMILY H. HuntingtoN*
}

From the point of view of the wage earner perhaps the most important sections of the unemployment insurance bills are those which deal with qualifications for receipt of benefits and the amount and duration of benefits. It is these aspects of the various state unemployment insurance laws which are the subject matter of this article. $^{1}$

Due to the fact that benefits in no case may be paid until contributions have accumulated for two years, ${ }^{2}$ the analysis attempted in this article, to paraphrase the words of the administrator of one of the unemployment insurance laws, is of "purely academic" interest. That this epithet will not be applicable two years from now is obvious. At present we have only the language of the statutes on which to base a discussion of the benefit provisions of the various plans. When the benefit provisions are put into effect two years from now, a variety of interpretations may be given to similar or identical language in the laws of the various states.

\section{Qualifications for Receipt of Benefit}

In order to receive unemployment insurance benefits a worker must have been an insured "employee" in an insured "employment," employed by an "employer" within the meaning of the act. This general question of coverage is not within the scope of this article as it will be discussed elsewhere in this volume. ${ }^{3}$ Mention should be made here, however, of the general coverage provision that a worker, in order to be

- A.B., 1917, University of California; M.A., 1923, Ph.D., 1928, Radcliffe. Assistant Professor of Economics, University of California, since 1930. Chairman, Heller Committee for Research in Social Economics, University of California, 1935. Author: "British Health and Unemployment Insurance and Standards of Living," Essays in Social Economics, University of California Press, 1935; "Providing for the Unemployed; An Immediate and a Long-Time Program," Papers and Proceedings of the Eleventh Annual Conference of the Pacific Coast Economic Association, 1932.

'The statutes analyzed in this article are the following: Social Security Act of Aug. 14, 1935, Public, No. 271, 74th Cong., rst Sess., tit. III, IX; Ala. Laws 1935, act. 447; Cal. Stat. 1935, c. 352; Dist. of Col., Public, No. 386, 74th Cong., Ist Sess. (1935); Mass. Laws 1935, C. 479 (Mass. Gen. LAws, c. 15IA); N. H. Laws 1935, c. 99; N. Y. Laws r935, c. 468 (N. Y. Consol. LAws c. 3I, art. 18); Ore. Laws 1935, Spec. Sess., c. 70; Utah Laws 1935, H. B. No. 86; Wash. Laws 1935, c. 145, WIs. Stat. (1935) c. 108.

In the footnotes following, citations to the foregoing statutes will indicate only the jurisdiction and the number of the section referred to.

${ }^{2}$ The Social Security Act so requires. Tit. IX, $\$ 903$ (a) (2).

${ }^{3}$ See Lotwin, Coverage of State Unemployment Compensation Laws, supra, p. 7. 
insured, must have been employed in an establishment employing more than a given number of workers. Four of the laws, Alabama, California, Massachusetts and Wisconsin include only those employers employing eight or more employees; ${ }^{4}$ New Hampshire, New York, Oregon, Utah and Washington include only those employing four or more, ${ }^{5}$ and the District of Columbia, those employing one or more. ${ }^{6}$ This almost universal disqualification of workers because they are employed in small establishments is unique in unemployment insurance legislation. It is unquestionably borrowed from workmen's compensation where, though it is undesirable, it does not make the scheme so unworkable. Workmen's compensation is not based on the accumulation of rights and therefore if the worker is unprotected at one time he does not lose accumulated rights in the future. In unemployment insurance however, if the worker is employed in a small establishment, he loses not only his current protection but all the accumulated rights over the preceding years. An employee who comes within the general coverage of the scheme, must also meet certain other conditions in order to qualify for the receipt of benefits.

All of the acts provide that a worker, in order to be eligible for the receipt of unemployment insurance benefits, must have been employed in an insured employment for a given number of weeks in the year preceding application for benefits. The purpose of such provisions is to establish the fact that the applicant for benefits has been for the specified period, a bona fide member of the insured population. Its purpose also is to simplify administration and to avoid the excessive costs of including in the scheme workers who have been in insured employment only a few weeks. There may be a considerable number of workers who occasionally take odd jobs and yet who are not really seeking employment regularly. It is important to distinguish between these and those who are intermittently but regularly employed. For example, a worker might be employed for only four weeks in a year and if benefits were allowed in the ratio of one week's benefit for four weeks of employment and if he were eligible for benefits he would receive one week's benefit. This would involve heavy administrative costs for, perhaps, negligible benefits. Disqualification of these workers would make it possible to pay more adequate benefits to the more stable members of the working population.

There is considerable variation in the laws with respect to the number of weeks of employment required in order to establish eligibility for unemployment insurance benefits. The shortest period is that of Wisconsin in which the worker must have been employed for more than four weeks and on at least twelve working days, or, if employed on a monthly salary, for at least one month. ${ }^{7}$ The New Hampshire law

'Ala. \$2 (f); Cal. \$9; Mass. \$I (c); Wis. \$\$108.02, x08.02I. This qualification is undoubtedly the result of the provision of the Federal Social Security Act, that only those employers are taxed who employ eight or more workers.

${ }^{5}$ N. H. \$I (v); N. Y. $\$ 502$ (3); Ore. $\$ 2$ (d); Utah, \$3 (e); Wash. \$3 (6).

DD. C. $\$ \$ I(a), 3(2)$.

${ }^{7}$ Wis. $\$ 108.04$ (9). This is cumulative from year to year. Letter from R. L. Hibbard, Unemployment Compensation Department, Industrial Commission of Wisconsin, Jan. 3, 1936. 
requires ten weeks of employment in the year preceding application for benefits. ${ }^{8}$ In the District of Columbia the period is 13 weeks in the preceding 52 weeks, and in New York and Massachusetts 15 weeks in the preceding year or 22 weeks in the two preceding years. ${ }^{9}$ Utah requires 20 weeks of employment in the preceding year; Alabama, Oregon and Washington 26 weeks in the preceding year or 40 weeks within the two preceding years, and California 26 weeks within the preceding year..$^{10}$ These great variations in the laws of the different states cannot be justified on any logical grounds. Apparently, the periods adopted were the result of compromise in the state legislatures.

The California law is the only one in which is found the additional provision that the applicant for benefits must have been a resident of the state for one year immediately preceding the beginning of unemployment. ${ }^{11}$ This requirement is undoubtedly the result of the fear, always prevalent in this state, of attracting nonresident workers. There seems, however, to be no good reason for this additional qualification in view of the relatively long period of previous employment required.

In addition to the requirements regarding length of employment all the unemployment insurance laws provide that the applicant for benefits must be physically able to work and available for work, and must register at and periodically report to an employment exchange. These provisions automatically exclude from benefits all persons whose unemployment is due to causes other than lack of available work and those who might continue to apply for benefits after they have obtained work.

Closely allied in purpose to the above provisions are those designed to prevent "malingering," chief among which is the typical provision that benefits will be denied if the applicant refuses "suitable" employment when offered. The determination of what is to be regarded as "suitable" employment is obviously a difficult one. The legislature must, in its efforts to protect the insurance fund against inroads by those who are unwilling to work, nevertheless guard against the possibility of the unemployment insurance scheme being used to depress wages and lower standards of working conditions, or being used as a weapon in industrial disputes. ${ }^{12}$

All of the acts require that the unemployed person must accept "suitable" employment. California, New York, Utah and Wisconsin deny benefits entirely, ${ }^{13}$ whereas, Alabama, the District of Columbia, Oregon, Massachusetts, New Hampshire and Washington merely extend the waiting period, with respect to the applicant who refuses to accept "suitable" employment. ${ }^{14}$

The definition of "suitable employment" varies somewhat, but there is substantial agreement in the laws that it is employment for which the worker is reasonably

${ }^{8}$ N. H. $\$ 2$ I.

'D. C. $\$ 10$ (a) (2); N. Y. $\$ 503$ (c); Mass. $\$ 18$ (a).

${ }^{10}$ Utah, $\$ 7$ (a) (I); Ala. $\$ 6$ (a); Ore. $\$ 4$ (a) (I); Wash. $\$ 7$ (I); Cal. $\$ 56$ (d).

II Cal. $\$ 56$ (d).

${ }^{10}$ See provisions of Social Security Act relating to "suitable" employment, infra, p. 23.

${ }^{23}$ Cal. $\$ 56$ (c); N. Y. $\$ 506$ (I); Utah, $\$ 8$ (a) (4); Wis. $\$ 108.04$ (6).

${ }^{14}$ Ala. $\$ 6$ (g); D. C. \$II (c); Ore. $\$ 4$ (b) (3); Mass. \$19 (c); N. H. \$27; Wash. \$7 (7). 
fitted, that it must be within a reasonable distance from his home and former work, and that it may be in non-insured as well as in insured employment. To these elements is sometimes added the provision that the work must not be detrimental to health, safety or morals, and that earnings must at least be equal to the unemployment benefit or the hours of work equal at least to half the hours normally worked in that occupation.

The Federal Social Security Act provides ${ }^{15}$ that no employment shall be deemed suitable (I) "if the position offered is vacant due directly to a strike, lockout, or other labor dispute"; (2) "if the wages, hours or other conditions of work offered are substantially less favorable to the individual than those prevailing for similar work in the locality"; and (3) "if as a condition of being employed the individual would be required to join a company union or to resign from or refrain from joining any bona fide labor organization." These provisions have been incorporated in all the state acts, since they are essential if credit is to be given for the federal tax.

The foregoing provisions to prevent employers from using the unemployment insurance plan as a weapon against organized labor are counter-balanced, in most of the bills, by provisions which deny benefits to workers who have lost their employment because of strike, lockout or other labor dispute. With the exception of New York in which there is a penalty of an extended waiting period, ${ }^{10}$ the denial lasts as long as the trade dispute is in active progress in the establishment in which the man was employed.

\section{Waiting Period}

Although the unemployed person qualifies for the receipt of unemployment insurance benefits, these benefits are not paid to him immediately, but only after a waiting period of several weeks. The purpose of the waiting period is to allow time for investigation of claims, to discourage malingering, to save the administrative costs in the payment of vast numbers of small claims, and to avoid frittering away the funds on periods of unemployment of very short duration.

In Alabama, the District of Columbia, Oregon and Wisconsin, the waiting period is three weeks. ${ }^{17}$ This is also the maximum waiting period in any one year. That is to say, the time during which the unemployed worker "waits" for benefits is cumulative, and when it totals three weeks, regardless of whether it runs consecutively or not, he is not required to wait for benefits if he becomes unemployed again that year. In New Hampshire and New York the waiting period is also three weeks, but this is not the maximum for any one year. ${ }^{18}$ In New Hampshire a waiting period of one week is required each time the worker becomes unemployed after the first three weeks of waiting have been served, except in situations where his

\footnotetext{
${ }^{15}$ Social Security Act, tit. IX, $\$ 903$ (a) (5).

${ }^{10}$ N. Y. $\$ 504$ (2) (b).

${ }^{17} \mathrm{Ala}$. $\$ 6$ (c); D. C. $\$ 10$ (a) (5); Ore. $\$ 5$ (a); Wis. $\$ 108.04$ (3).

${ }^{18}$ N. H. $\$ 23 ;$ N. Y. $\$ 504$ (I).
} 
previous unemployment occurred within the preceding 13 weeks; thus a waiting period totaling six weeks in one year might conceivably be required. In New York the maximum waiting period in any one year is five weeks. California and Massachusetts require a four weeks waiting period, with a maximum of four weeks in one year, Washington six weeks with a yearly maximum of six weeks, and Utah two weeks with a yearly maximum of eight weeks. ${ }^{19}$

The waiting periods required under the various laws seem to fall into two categories, those which are three or four weeks and have as their primary purpose the prevention of malingering and the simplification of administration, and those which are longer and whose chief aim is to restrict insurance protection to the workers who suffer relatively long periods of unemployment. The advisability of disqualifying an unemployed worker from the receipt of benefits for a period as long as six weeks is open to question. Since the usual earnings of the worker at full employment, in most cases, do not amount to more than $\$ 1500$ a year, scarcely a "saving" wage, and since the worker has probably already borne some of the burden of unemployment in reduced earnings, it would seem that six weeks without any wage or substitute for wage is too long a period.

An additional waiting period is usually required if the employee has voluntarily left his employment or has been discharged for misconduct. The laws of New York, Wisconsin, and Utah absolutely deny benefits to the worker who voluntarily leaves his employment. ${ }^{20}$ The other states merely increase the waiting period if the employee has voluntarily left his employment, the usual method being to double the length of the waiting period, although the State of Washington increases it from six to eight weeks and Oregon from three to seven weeks. ${ }^{21}$ In cases where the worker has been discharged for misconduct, four of the laws, California, Massachusetts, New Hampshire and Wisconsin, double the waiting period; three, Alabama, the District of Columbia and Washington, provide increased waiting periods within prescribed limits; New York increases the waiting period more than threefold, from three to ten weeks, and Oregon increases it from three to seven weeks. ${ }^{22}$ Utah makes no specific provision for the employee discharged because of misconduct. To double the waiting period as a penalty for voluntary loss of employment would seem adequate; to increase it more than this seems unjustified. The increased waiting period in cases where the worker voluntarily leaves his employment or is discharged for misconduct is in the nature of a penalty, intended to discourage workers from voluntarily causing their own unemployment in reliance upon their right to benefits. As previously stated, in a number of the laws the waiting period is also increased

${ }^{10}$ Cal. \$54; Mass. \$17; Wash. \$7 (3); Utah, \$6 (a).

${ }^{20}$ N. Y. $\$ 506(\mathrm{I})$; Wis. $\$ 108.04(4 \mathrm{~m})(\mathrm{b}) ;$ Utah, $\$ 8$. The New York and Utah statutes are not entirely clear on this point.

${ }^{21}$ Wash. $\$ 7$ (5); Ore. $\$ 4$ (b) (2).

$\approx$ Cal. §55; Mass. §19 (b); N. H. \$26; Wis. \$108.04 (4m) (a); Ala. §6 (f); D. C. \$1 (b); Wash. $\$ 7$ (6); N. Y. $\$ 504$ (2) (2); Ore. $\$ 4$ (b) (2). 
in cases where the worker refused to accept "suitable" employment when offered. These are the laws of Alabama, the District of Columbia, Oregon, Massachusetts, New Hampshire and Washington. ${ }^{23}$ Presumably this means that, if an employee refuses to accept employment which is deemed suitable by the administrative authority, he will be penalized by an increased waiting period. If at the end of this period however, suitable employment is not available he will be granted benefits. This seems justifiable in view of the difficulty in defining "suitable" employment. It should not be made too easy for the worker to refuse employment but on the other hand he should not be denied all benefits merely because at some time he has refused work which appeared to him to be entirely unsuitable.

The unusual provision, found only in the New York law, ${ }^{24}$ that an employee who is unemployed due to a strike or lockout may be granted benefits after an increased waiting period of ten weeks was probably put into the law by organized labor with a view to giving unemployment insurance benefits after ten weeks to the worker who left his job because of a labor dispute, although the labor dispute might still be in progress. It would seem however that this provision may be a boomerang because the worker will be denied benefits for ten weeks if he is not reëmployed, even though the dispute may have been settled. The states which deny benefits during the progress of a labor dispute will, on the other hand, grant benefits immediately on the settlement of the dispute, after the required regular waiting period.

\section{Benefit Rates}

If the unemployed worker has worked for an employer and in an employment subject to the act and has met the qualifying conditions, he is eligible to receive unemployment insurance benefits. The problems to be discussed here are the amount of the benefit in case of total and partial unemployment, the provisions for the part-time employee and for seasonal uneinployment. The length of time for which benefits are paid and the restrictions on benefits will be discussed in the succeeding section.

\section{Total Unemployment}

Benefits are a substitute for wages in periods of unemployment. If the benefit equalled the wage it would encourage malingering, and, moreover, the cost would be so high as to be impractical. If, on the other hand, it is too meager, it will not fulfill its purpose. There must be a compromise somewhere between these limits.

In all of the laws, the unemployment insurance benefit is a percentage of wage rather than a flat rate, but a maximum and, in most states, a minimum amount is specified. The benefit is 50 per cent of weekly wage in all of the laws except that

\footnotetext{
${ }^{23}$ Ala. $\$ 6$ (g); D. C. $\$ 1 I$ (c); Ore. $\$ 4$ (b) (3); Mass. \$I9 (c); N. H. \$27; Wash. \$7 (7).

${ }^{24}$ N. Y. $\$ 504$ (2) (b).
} 
of the District of Columbia. The District of Columbia follows the principle laid down by most of the European unemployment insurance laws in varying the benefits in relation to the number of dependents in the family; it allows $4^{\circ}$ per cent of the weekly wage for a single person, 50 per cent for a man and dependent wife and five per cent additional for each dependent relative. ${ }^{25}$

All but three of the laws, Alabama, the District of Columbia and Washington, set a limit below which benefits may not fall. In California and Oregon the minimum is $\$ 7.00$ a week, in Utah $\$ 6.00$ and in the remaining four states it is $\$ 5.00$, although in New Hampshire there is a further limitation in that the benefit may never be more than 75 per cent of the wage. ${ }^{26}$

All of the laws are faulty in fixing benefits at the same percentage of wage for all wage classes (except as the maximum and minimum amounts vary the percentage in the highest and lowest wage groups), in setting too low a maximum and in failing, in all but one instance-the District of Columbia, to provide extra benefits for dependents. The problem of arranging a more equitable scale of benefits would be greatly simplified if it were possible to relate benefits to an objective standard of living. The low wage scales, prevailing even in a time of relative prosperity, make this impossible, since, if unemployment insurance benefits were related to an objective standard of living they would, in many cases, be higher than wages. The best alternative is to relate benefits to wages, since in this way they will at least be related to the worker's actual plane of living. On this theory the states have fixed benefits at a percentage of wage rather than at a flat rate. However, if benefits are related to wages, a higher percentage (of wage) should be given to the lower paid workers than is given to the higher paid workers, in order to avoid reducing benefits to the lower wage group to an impossibly small amount. Also additional benefits should be given to workers with dependents; the reason being that wage bears no relation to size of family, and when only a portion of wage is given as benefits, the worker with a large family suffers greatly. If the benefit is considered as a mere pittance to enable the unemployed person and his family merely to eke out an existence, 50 per cent of the wage, with a maximum of $\$ 15.00$, may perform this function. A flexible scale of benefits is suggested below, so arranged that the lower paid worker will receive a higher proportion of his wage in benefits than the higher paid worker. In order to simplify administration, wage classes should be set up and the benefit for those who fall into each wage class should be based on a specified wage. ${ }^{27}$

\footnotetext{
${ }^{2}$ D. C. $\$$ I (g), defines "dependent relative" as "a mother, father, stepmother, stepfather, brother, or sister, who, because of age or physical disability, is unable to work, or a child under sixteen years of age, who is wholly or mainly supported by the individual receiving the benefit."

${ }^{2}$ Cal. $\$ 58$ (a); Ore. $\$ 3$ (a); Utah, $\$ 6$ (b) (2); Mass. \$20; N. H. \$r4; N. Y. \$505 (1); Wis. $\$ 108.05(\mathrm{r})$.

${ }^{\pi}$ For a similar but somewhat lower seale of benefits, see Douglas, Standards of UNEMpLoyment INSURANCE (1933) 89.
} 


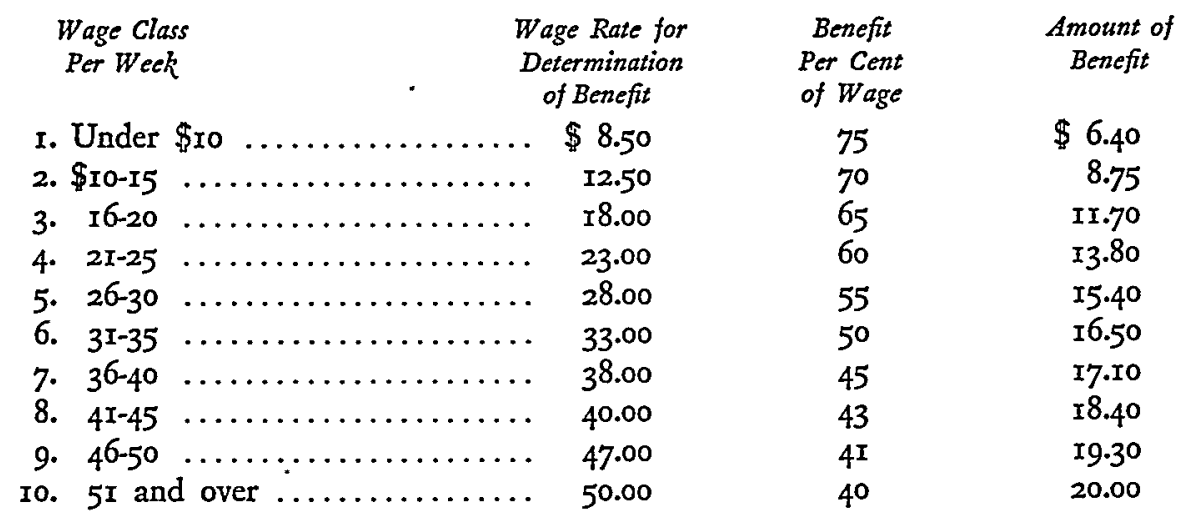

The benefits suggested for the lower wage groups are clearly inadequate, but this is unavoidable if benefits are not to so closely approximate wage as to discourage job-hunting. The single unemployed worker can, except in the very low wage classes, manage to get along on the benefits suggested in the table. In all but the highest wage groups the benefits in the table are not adequate for the worker with dependents. It is therefore suggested that five per cent be added to the benefit for each dependent, dependents being defined as in the District of Columbia Law. ${ }^{28}$ A limitation should however be put on this proviso in order that benefits in the lower income classes shall not equal or exceed wages and that in the upper income classes benefits shall not be so high as to deter people from accepting employment. It is suggested that there should be a maximum of 75 per cent of wage and a maximum amount of $\$ 20.00$ a week, including the addition for dependents. This would give greater assistance to those in the middle than in the extremes of the income classes. It is justifiable on the grounds stated above and also on the theory that a good many of those in the very low income groups will not have dependents and that $\$ 20.00$ a week is enough to maintain temporarily most of the families with the higher incomes. The budget prepared by the Heller Committee for Research in Social Economics for dependent families, in November $1934{ }^{29}$ shows that in San Francisco at that time a family of four, which is slightly larger than the "census family" for that area, could get along temporarily, without sacrificing the primary needs, on a little less than $\$ 80.00$ a month. It is of course realized that prices and conditions differ through the country and this figure is therefore only a rough approximation. It is quoted merely to show that in districts where the wage scale is such that the maximum of $\$ 20.00$ a week would be reached, it would supply the necessities of life.

The benefits so far discussed are payable to the worker who is totally unemployed. Total unemployment is almost unanimously defined as total loss of wages, although

\footnotetext{
${ }^{28}$ See note 25 , supra.

${ }^{20}$ Heller Committee for Research in Social Economics, Quantity and Cost Budgets, Univ, of California, Berkeley, Cal. (r935) $4 \mathrm{I}$.
} 
Wisconsin classifies the worker as totally unemployed even though he may be earning something at "odd jobs." 30 In this respect the Wisconsin act merely recognizes what will, in fact, probably be the practical situation in all cases. Unless the unemployed worker were required to remain almost continuously at the employment exchange it would be impossible to disqualify him from benefits because he could occasionally find an "odd job." It is probably better administrative policy to recognize this than to insist on the letter of the law which would inevitably force prevarication on the worker.

\section{Partial Unemployment}

In addition to the payment of benefits to the worker who is totally unemployed, there is also need for benefits in the case of partial unemployment. Throughout a year a person who has been only partially employed may lose as much, or more, in earnings as one who has been employed full-time for part of the year and totally unemployed for the other part.

All of the laws except those of Massachusetts, New York and Utah provide for the payment of benefits in case of partial unemployment. The provisions regarding benefits for partial unemployment reveal two somewhat different theories. The laws of California, New Hampshire and Wisconsin do not consider the worker eligible for benefits for partial unemployment unless he has received in wages less than his weekly benefit rate for total unemployment. ${ }^{31}$ The laws of Alabama, the District of Columbia, Oregon and Washington, on the other hand, make the worker eligible for such benefits if he has earned a small amount above his total unemployment benefit. $^{32}$

The following table shows the amount of benefit which would be received by the partially unemployed worker whose full time wage is $\$ 20.00$ a week, but who under conditions of partial unemployment is earning only $\$ 10.00$.

\begin{tabular}{|c|c|c|c|}
\hline State & $\begin{array}{l}\text { Earnings } \\
\text { per Week }\end{array}$ & $\begin{array}{c}\text { Benefit for } \\
\text { Partial } \\
\text { Unemployment }\end{array}$ & $\begin{array}{l}\text { Total Earning } \\
\text { and Benefit }\end{array}$ \\
\hline California $\ldots .$. & $\$ 10.00$ & none & $\$ 10.00$ \\
\hline New Hampshire & 10.00 & none & 10.00 \\
\hline Wisconsin $\ldots$. & 10.00 & none & 10.00 \\
\hline Alabama $\ldots \ldots \ldots \ldots \ldots \ldots$ & 10.00 & $\$ 2.00$ & I2.00 \\
\hline District of Columbia ........... & 10.00 & 2.00 & 12.00 \\
\hline Oregon $\ldots \ldots \ldots \ldots \ldots \ldots \ldots \ldots$ & 10.00 & 2.00 & 12.00 \\
\hline Washington,$\ldots \ldots \ldots \ldots \ldots \ldots$ & 10.00 & 1.00 & Ir.00 \\
\hline
\end{tabular}

Alabama, the District of Columbia and Oregon allow the total of earnings plus benefit for partial unemployment benefit to be $\$ 2.00$ more than would be the benefit for total unemployment, whereas Washington allows it to be $\$$ r.00 more. ${ }^{33}$ In the

${ }^{20}$ Wis. $\$$ r08.05 (3).

${ }^{31}$ Cal. \$53; N. H. \$I (xI); Wis. \$108.02 (q).

${ }^{80}$ Ala. $\$ 5$ (c); D. C. $\$ 1$ (f); Ore. $\$ 2$ (k); Wash. $\$ 6$ (3).

${ }^{*}$ Ibid. 
other three states, if earnings are less than the benefit for total unemployment, a benefit is allowed sufficient in amount to bring the total of wages and benefit to $\$ 10.00$, the benefit for total unemployment for a worker earning $\$ 20.00$ a week.

There is a serious question of adjusting benefits for partial unemployment so that the worker will be encouraged to retain his job. If as in California, New Hampshire and Wisconsin, the worker is not permitted to receive any benefit for partial unemployment if his wage (for partial employment) is as great as the benefit he would receive if totally unemployed, the incentive to keep his job is not very strong. In those states which place the partially unemployed worker in a slightly better position than one who is totally unemployed by permitting him to receive a small benefit in addition to wage, within circumscribed limits, there is a strong inducement to accept partial employment. ${ }^{34}$

\section{Part-Time Employment}

Another group who need the protection of unemployment insurance are part-time workers. Part-time workers are generally defined as persons who, for reasons personal to themselves, are unable to work the usual full time and who customarily work less than full-time. Wisconsin's definition is somewhat different in that it places in the category of part-time workers only those who customarily work less than half-time. ${ }^{35}$

Six of the laws, those of California, Massachusetts, New Hampshire, New York, Oregon and Wisconsin place part-time workers in the category of those who may receive unemployment insurance benefits. ${ }^{36}$ In all of these states except Wisconsin, the time which the employee normally works is considered to be his full-time employment and the commission is given the responsibility for setting up special conditions under which benefits may be received and the amount of the benefit. The Wisconsin act provides that for the purpose of determining benefits for these workers, full-time hours shall be considered to be one-half the usual weekly hours. Furthermore the Wisconsin law denies benefits for partial unemployment to parttime workers, whereas the other states apparently allow benefits for partial unemployment to part-time workers.

Although it is probable that some part-time workers do not need the protection of unemployment insurance as much as full-time workers, a great many, such as women who work part-time in department stores, depend upon their earnings for a large part of their livelihood and should have protection in case all or part of their earnings are cut off by unemployment. There is some danger that granting unemployment benefits to part-time workers may bring within the scheme some workers who are not bona fide members of the labor supply. It would seem however that

\footnotetext{
"For a discussion of this problem see Hansen, Murray, Stevenson, Stewart, A Program for UnempLoyment INSURANCE and ReLIEF in the UNITED States (I934) 80-82.

${ }^{3}$ Wis. $\$ 108.04(4)$.

${ }^{50}$ Cal. \$60; Mass. \$27; N. H. \$20; N. Y. \$509; Ore. \$3 (c); Wis. §108.04 (4).
} 
protection against this danger will be provided by the special qualifications which the administrative authorities are authorized to require for the receipt of benefits by part-time workers.

\section{Seasonal Employment}

The protection of the worker subject to regularly recurring periods of seasonal unemployment also raises a number of questions which must be considered in formulating unemployment insurance legislation. It has been suggested by some that the seasonal worker is compensated for his lost time by higher wages when he is employed and that the worker can therefore save for the definitely predictable periods of unemployment. It is further maintained that payment of benefits for seasonal unemployment will so deplete the unemployment insurance fund that only meager benefits will be available to those suffering from unemployment which is not caused by the seasonal character of the industry. ${ }^{37}$ The facts are, however, that, although some highly skilled workers in seasonal occupations receive wages weighted for this factor, many of the unorganized and unskilled workers attached to these trades have no such addition made to their wages, and furthermore, that seasonal unemployment is not distributed evenly among those in a given trade or occupation. Another difficulty must also be mentioned. Workers in seasonal industries suffer also from unemployment not of a seasonal character, so that there is no justification for completely excluding them from benefits.

It is however, probably necessary to protect the unemployment insurance fund against the inroads of benefits to workers for seasonal unemployment. On the other hand, benefits should be allowed to workers in seasonal industries for unemployment which is not seasonal in character. This could be accomplished by special rules and regulations restricting benefits to unemployment occurring in those periods of the year in which the worker might reasonably be expected to find employment in his industry. If any benefits are to be given to seasonal workers, the qualifying period of employment must be shortened. Otherwise, the vast majority of workers in seasonal employments could probably not qualify for benefits. ${ }^{38}$

Only four of the laws make special provisions for seasonal unemployment. Presumably it is the intention of the legislatures of these states that benefits should be given to seasonal workers only during the period of the year during which they are customarily employed. Massachusetts defines seasonal industries or occupations as those in which it is customary to operate only during regularly recurring periods of less than one year and in which there are individuals who are ordinarily not employed during the year in any other employment. ${ }^{30}$ It is left to the unemployment compensation commission to determine which industries or occupations are to be

\footnotetext{
${ }^{n}$ For a discussion of this subject, see Myers, Seasonal Unemployment Insturance (1931) 21 Axs. Econ. REv. 416-426.

${ }^{33}$ For a discussion of these problems, see Douglas, op. cit. supra note 27, at 52-56; and HaNsBN, Murray, Stevenson, Stewart, op. cit. supra note 34, at 122-r23.

${ }^{20}$ Mass. $\$ 26$.
} 
deemed seasonal and the length of such seasonal periods, and to modify the requirements for eligibility to benefits in such a manner that individuals employed in seasonal industries or occupations will receive benefits in reasonable proportion to the length of time during which they have been employed in such industry or occupation.

New York defines seasonal industries or occupations as those in which it is customary to operate not more than 18 weeks in a year and in which there are individuals who are not ordinarily employed during the year in any other employment. ${ }^{40}$ It is left to the commissioner to determine the seasonal period and to modify the requirements for eligibility to benefits under the same general rules as in Massachusetts. The Oregon act provides that whenever it is customary to operate only during regularly recurring periods of less than one year, benefits shall be restricted to unem. ployment occurring in those periods. ${ }^{41}$ It is left to the unemployment compensation commission to determine the seasonal periods and to modify the requirements for eligibility to benefits under the same general rules as in Massachusetts. Since the general rule in Massachusetts and Oregon is that employers are exempt from the scheme unless they operate for as long as 20 weeks a year, the special rules regarding seasonal industries will presumably have to apply to those who operate for some period longer than 20 weeks.

Utah exempts any seasonal industry in which it is customary to work not more than twelve weeks in twelve months. ${ }^{42}$ Under the Utah act, there are no provisions for special rules and regulations in regard to benefits to the seasonal worker. $\mathrm{He}$ is either disqualified from the receipt of benefits entirely or receives regular benefits. The Utah act is, in fact, similar to the remaining six laws in which are found no special provisions for seasonal unemployment. With the exception of the District of Columbia, in which there is no such limitation, all of these provide that in order to be covered an employer must have operated his plant for a given number of weeks. Alabama and California require 20 weeks, Wisconsin 18, and New Hampshire and Washington $13 .{ }^{43}$ If the "season" does not last longer than these periods, the employer and his employees will be exempted from the scheme. Furthermore, these laws also require that the employee must have fulfilled a qualifying period in insurable employment. Both of these provisions will effect the number of seasonal workers covered. In cases where the above periods are long, a great many seasonal workers may be excluded from benefits, and where they are short, the burden of seasonal unemployment on the fund will be great.

\section{Duration of Benefits}

We next come to the problem of how long will benefits be paid to an unemployed worker. In all of the laws the length of time for which benefits will be paid is related to the length of time that the worker has been employed in an insured

\footnotetext{
${ }^{10} \mathrm{~N} . \mathrm{Y} . \$ 508$.

"Ore. $\$ 7$ (a).

${ }^{2}$ Utah, 54 .

"Ala. \$2 (f); Cal. \$9; Wis. \$\$108.02, I08.021; N. H. \$I (v); Wash. \$3 (6).
} 
employment-in other words, to the length of time for which contributions have been made. The most usual ratio of benefits to contributions for ordinary benefits is one week's benefit to four week's contributions. This is followed in the laws of Alabama, California, Massachusetts, New Hampshire, Oregon, Washington, and in Wisconsin for those whose weekly benefit rate is $\$ 10.00$ or less. ${ }^{44}$ In the District of Columbia and Utah, the ratio is one to three, and in New York one week's benefit to 15 day's employment. ${ }^{45}$

All but four of the laws limit the duration of ordinary benefits to 16 weeks in one year. In California, benefits are limited to 13 weeks in one year if less than ro4 contributions have been made, and 20 weeks in one year if more than 104 contributions have been made. ${ }^{40}$ In Washington the maximum in one year is 15 weeks and in Wisconsin it varies from $I_{3}$ for those who receive benefits of $\$$ ro.00 or less to nine for those who receive $\$ 15.00$ in benefits. ${ }^{47}$

There is considerable difficulty in interpreting the meaning of some of the statutes in regard to the length of time during which benefits will be paid. Attempts were made to secure interpretations from the various state commissions, with no success except in one case in which the administrator ventured to give an unofficial interpretation. The laws of New York, Utah and Wisconsin state definitely that no benefits will be given during more than a year after employment was lost. ${ }^{48}$ The result of this provision, together with the maximum weeks of benefit allowed in any one year, is that even though the worker may have had many years of steady employment he can draw benefits only during one year, and for a limited time within that year. In New York, for instance, where the ratio is one week's benefit to two and a half weeks of employment, only 16 weeks of benefit are allowed in any one year and benefits are only given during one year after loss of employment; the maximum length of benefit is 16 weeks, which gives the worker credit for only $4^{0}$ weeks of employment. A similar situation exists in Utah, where credit is given for only $4^{8}$ weeks of employment, and in Wisconsin, where credit is given for only 52 weeks for those receiving the lowest benefits. In these acts, if an employee has drawn his maximum weeks of benefit in a year, he must apparently again fulfill the same requirement as to employment, as would an employee who had never before been a member of the scheme, before receiving further benefits.

The California law is the most generous as to the length of time for which benefits will be given. ${ }^{40}$ If an employee has had many years of steady employment and is employed each year as much as 26 weeks in insured employment he may receive benefits each year based on his past weeks of employment. As long as he (I) (a).

"Ala. $\$ 5$ (d); Cal. $\$ 58$ (c); Mass. \$21; N. H. \$16; Ore. \$3 (b); Wash. \$6 (4); Wis. \$ro8.06
${ }^{15}$ D. C. $\$ 8$ (b) (1); Utah, $\$ 5$ (c); N. Y. $\$ 503$ (3) (e).
${ }^{10}$ Cal. $\$ 58$ (c).
${ }^{17}$ Wash. $\$ 6(5)$; Wis. $\$ 108.06$ (I) (a)-(c).
${ }^{4}$ N. Y. $\$ 503$ (3) (d); Utah, $\$ 5$ (d); Wis. \$ro8.06.
${ }^{\infty}$ Cal. $\$ 58(\mathrm{c})$. 
has had as much as 104 weeks of contribution against which benefits have not been charged, he may receive 20 weeks of benefit and if he has had less than ro4, he may receive one week's benefit for four weeks' contribution with a maximum of 13 weeks in one year. The result of this will be to give a considerable degree of security for some years to those who have had long periods of steady employment.

Oregon allows one week's benefit for each four weeks of contribution within I04 weeks preceding unemployment. ${ }^{50}$ This makes it possible for the worker who has been in insured employment for 26 weeks in the year preceding his application for benefits, to draw benefits on his past ro4 weeks of employment. He could therefore receive 15 weeks of benefit in one year and eleven in the second.

Alabama, the District of Columbia, Massachusetts, New Hampshire and Washington also provide for "additional" benefits. 51 "Additional" benefits are for the purpose of giving the worker who has been employed continuously for several years some extra payments. They are, however, rather strictly limited in order to conserve the fund. The ratios for these benefits are in Alabama and the District of Columbia one week's benefit to 20 weeks of employment during the preceding 260 weeks; in Massachusetts, one week's benefit to I8 weeks of employment within six years and then one week's benefit for 26 weeks of employment prior to the six preceding years; New Hampshire, one week's benefit for 24 weeks of employment, with a maximum of ten weeks' (additional) benefits, and Washington, one week's benefit for $x 6$ weeks of employment within the 260 preceding weeks.

The greatest difficulty of interpretation is found in those laws which provide for normal and additional benefits. The Alabama law may be used for purposes of illustration. This law allows regular benefits in the ratio of one week's benefit to four weeks of employment within the I04 weeks preceding unemployment, and allows additional benefits in the ratio of one week's benefit to 20 weeks of employment within the 260 preceding weeks. This would seem to give 26 weeks of benefit, but there is a maximum of 16 weeks. Sixteen weeks of benefit would use up 64 weeks of contribution. The question arises as to whether he would receive the remaining ten weeks of regular benefits in the following year and then the additional benefits, or whether additional benefits begin at the close of the r6 weeks' period and are based on the difference between the 64 and 260 weeks which is the maximum number of weeks on which additional benefits may be given.

Although no authoritative judgment can as yet be given on this problem, either as to Alabama or any other state having like provisions, the consensus of opinion seems to be that regular benefits are limited to the maximum allowed in one year, and that additional benefits follow immediately on regular benefits. When these additional benefits have been granted, the worker will have received benefits based on all previous weeks of employment and no further benefits will be available until

${ }^{\infty}$ Ore. $\$ 3(\mathrm{~b})$.

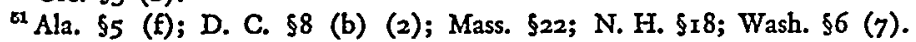


the worker has again been employed for the qualifying period. Except in the case of Massachusetts, ${ }^{52}$ in which the qualifying period of employment for those who have drawn the maximum benefit is reduced from 15 to eight weeks, all of the laws apparently require that the same qualifying period be met as for newly employed individuals.

The following table shows the number of weeks of benefit allowed to a worker who has been steadily employed for ten years.

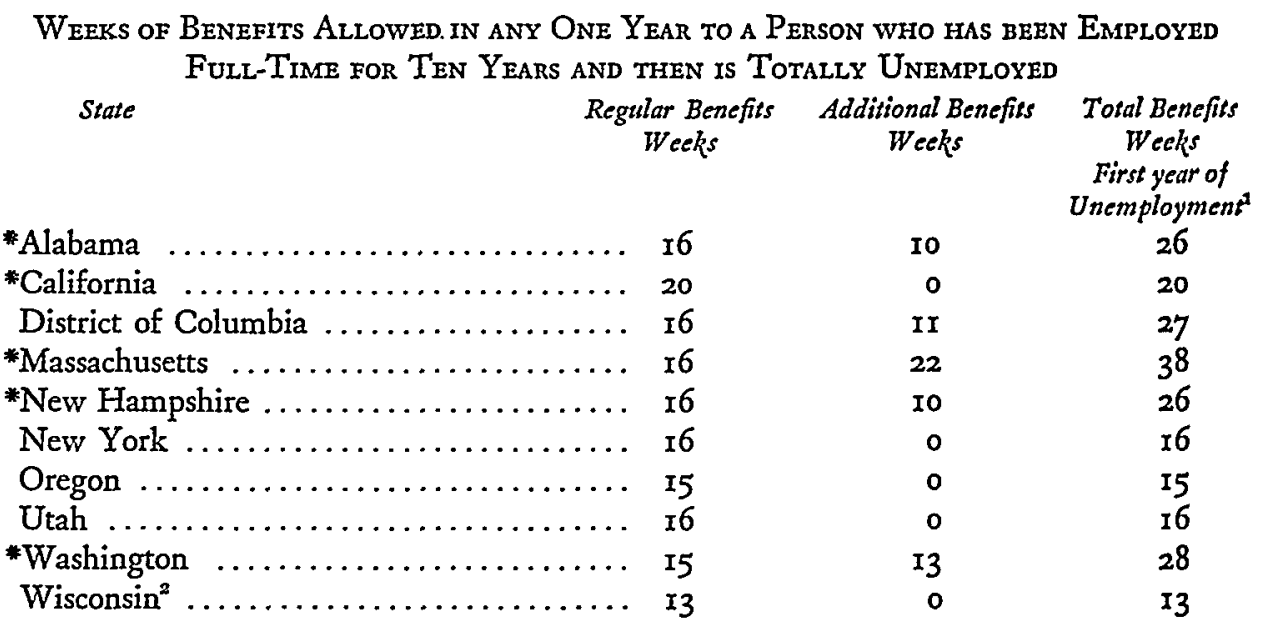

- States requiring contributions from employees.

1 With the exception of California and Oregon, workers who had been steadily employed for ten years, would, in one year, use up all previous weeks of employment on which benefits would be granted. In Massachusetts, under circumstances of very long employment, nearly 20 years, benefits, based on past weeks of employment would also be paid in the second year of unemployment.

${ }^{2}$ Schedule applicable only to those with weekly benefits of $\$ 10.00$ or less. If benefit $\$ 12.50$, ten weeks benefit given; if benefit $\$ 15.00$, nine weeks benefit given.

In general, the laws which require an employee contribution provide more generous benefits than do those in which the burden is borne entirely by the employer. California, with an employee contribution, gives the most generous credit for previous contributions in the determination of unemployment insurance benefits. The other states with employee contributions allow from 26 to 38 weeks of total benefit whereas those without employee contributions allow in general only from 13 to 16 weeks of total benefit. There are two exceptions to these general rules. The District of Columbia provides a relatively long benefit period but no employee contributions; however there are contributions from the government. Oregon, without employee contributions, provides 26 weeks of total benefit which puts it in the class of the states in which employees also contribute..$^{53}$

In addition to the restrictions on benefits already discussed, all of the acts either explicitly, by giving the administrative authority the power to reduce or cease to pay benefits, or implicitly, by stating that the unemployment insurance fund shall be the sole source of benefits, make it possible to limit benefits in such a fashion as 
to maintain the solvency of the fund. In the light of the fact that information as to the actuarial basis of these schemes is almost completely lacking, this is probably essential. At such time as information is available as to the probable amount and duration of unemployment it should be possible to determine in advance that a given contribution will provide definite benefits for definite periods of time. Unemployment insurance can probably never provide benefits from its regular fund for excessively long periods of unemployment. To meet this problem there will have to be set up a system of emergency benefits, supported not from the insurance fund but from public funds. The question as to how long these emergency benefits should be given, and under what conditions, is not within the scope of this article, but it would seem that they should be in some way attached to the unemployment insurance scheme rather than to the organization which handles poor relief.

\section{Conclusions}

The general conclusions from the foregoing analysis of the benefit provisions of the unemployment insurance laws now on the statute books in the United States is that, although there is much similarity in the provisions, the differences are such that equal protection is not afforded all workers in the several jurisdictions. Moreover, great variations are inevitable, if each state is permitted to draft its own legislation with very little advice or assistance from the federal government. As has been pointed out, the federal government has set up certain standards as to coverage and as to conditions under which a worker may not be disqualified for the receipt of benefits, if advantage is to be taken of the credit for the federal tax. If, however, it had included a more rigid set of standards, as was the desire of the staff of the President's Committee on Economic Security, as well as of the majority of the advisory council to that committee, there would have been more uniformity in the legislation. It must be pointed out that while this would not have guaranteed better than standard conditions, it would have been justified on the basis of equal treatment of the worker regardless of his residence. It would presumably have set up reasonable protection for the worker and would have prevented some states from passing laws which fail to provide at least that amount of protection.

It should be pointed out that since the rate of unemployment varies so much from state to state, the federal government could not have required state laws to grant standard benefits which could not possibly have been supported by uniform taxes or rates of contribution. It is to be remarked, however, that the actual variations in the amount and duration of benefits is in no way related to this scientific principle, but to legislative accident. The experts on the staff of the Social Security Board were unanimous in their belief that adequate unemployment insurance could never be achieved through the action of forty-eight separate states. While conceding that political considerations might make temporary state experiments inevitable they were convinced that ultimately a federal scheme would be inescapable. This is related to the obvious fact that states are political rather than economic units. 